\title{
Mechanical Engineering Excellence Program Cultivation Model: Exploration and Practice
}

\author{
Yongbin Lai, a , Xiu Chen², Zhang xin ${ }^{1}$, Qinhua Chen ${ }^{1}$, Yijun zhou ${ }^{1}$, Guang wu ${ }^{1}$, \\ Xuebin $\mathrm{li}^{1}$, Long Wang ${ }^{1}$ \\ ${ }^{1}$ School of Mechanical Engineering, Anhui University of Science \& Technology, Huainan 232001, \\ China; \\ ${ }^{2}$ School of Chemical Engineering, Anhui University of Science \& Technology, Huainan 232001, \\ China. \\ ayblai@163.com
}

Keywords: Mechanical engineering, excellence program, talent training mode; practice base.

\begin{abstract}
According to the excellence program requirements, the participating colleges and universities should be combined with their own objective reality, formulate policies and measures of talent training flexibly to guarantee the implementation and the expected effect of the excellence program. In this paper, combined with the actual situation of our own university discusses the excellent engineers specialized in mechanical engineering cultivating idea, training standards, training scheme, teaching staff and training base construction, school-enterprise cooperation mechanism and other measures. As higher learning institution with distinctive industry background and characteristics, should be based on their own advantages and characteristics, directing at the industry demand build excellence program talent training system consistent with the orientation of school-running.
\end{abstract}

\section{Introduction}

Excellent engineer education and training programs(excellence program for short) is a major reform project to implement the Long-term Education Reform and Development Plan (2010-2020) and the national long-term talent development program (2010-2020), also is a major initiative to promote a change from a great nation of engineering education to a powerful country in higher engineering education, aiming at training a large number of high-quality engineering technique talents with strong innovation ability and economical and social development, serving the nation to walk a new industrialization path, build an innovation nation and talents strategy, playing a quite significant demonstration and guidance to promote the tertiary education to face the social demand cultivating talents, and comprehensively improve the quality of engineering education personnel training.

China's machinery and other engineering professional training mode have more drawbacks than developed countries. Heavy theory, light practice; much classroom, little outside class; profound, not comprehensive; heavy indoctrination, light self-study, and cultivating talents don't meet the requirements of social every vocation. How to take the social demand as the guidance, set against a backdrop of engineering practice, take engineering technology as the main line to deepen engineering training mode reform of professional talents, have aroused serious concern to colleges and universities.

\section{The guiding ideology and training target of excellence program in mechanical engineering specialty}

Formulated the engineering guiding ideology of industry-oriented, facing the future and the world under the ministry of education outstanding engineers training plan guiding ideology. Excellence Program should take the social demand as the guidance, set against a backdrop of engineering 
practice, take engineering technology as the main line, focus on improving students' engineering awareness and cultivating students' engineering quality and engineering practice ability. Fully integrating China's education power, enhancing own innovation ability, the development strategy of the innovative national construction, excellent engineer training ideas based on heavy foundation, heavy design, heavy create, through the research on the development of machinery industry and the demand for talents, compile training program of mechanical engineering professional excellent engineer. Combing with industry background and market demand characteristics, taking the improvement of the knowledge structure, strengthening the comprehensive ability and improving the engineering quality as cultivating core, through engineering connotation constantly enriches, students 'knowledge structure optimization, students' quality reinforcement, comprehensive engineering practice education under enterprise and social environment, gradually enhance students' engineering awareness, engineering quality, engineering practice ability, engineering design capability and engineering innovation and cultivate innovative excellence engineers with international competition capacity.

Mechanical engineering can provide a great deal of professional talents for China's construction machinery, mining machinery, agricultural machinery, chemical machinery, etc, and also is one of the three major traditional advantages of professional in Anhui University of Science \& Technology, professional wide coverage and strong practical engineering. Its professional features not only require further improving talents training quality, but also strengthen the engineering practice education, improve students' engineering practice ability and the ability to solve practical problems.

Accordingly, Anhui University of Science \& Technology has began to implement excellent engineers education and training program since April 2011, aiming at mechanical engineering professionals characteristics and patterns of growth, combing with excellence program requirements of the times, has formulated the enterprise training program, professional training programs and the curriculum system and has carried out the exploration and practice in many aspects about training standards of mechanical engineering excellent engineers.

\section{Cultivating ideas and concept innovation}

(1) According to the excellence program requirements, the cultivation of excellent engineers, engineering educational philosophy should permeate the whole teaching, teaching reform focuses on curriculum system and training, pays special attention to students' engineering consciousness, application design ability, the ability to analyze and solve practical problems.

(2) Teaching contents and curriculum system should reflect the mainstream technology and the latest development of machinery industry, in teaching organization forms, practice, management system and operational mechanism and other aspects should be bold in practice and innovation. In particular, reform practice teaching, strengthen the comprehensive engineering practice under enterprises and social environment, promote the talent training combined with productive labor and social practice.

(3) Strive for establishing students' practice, practice and carry out joint base of graduation design with international and domestic industry leader and strong enterprises; actively explore and establish the effective mechanism of students going to factories and enterprises to carry out practical internship practice; set up students' practical internship assessment mechanism of schools, employers units and industry sectors all participating in. Enable students experience the design development and management process of the enterprise, and improve the professional quality and accountability.

(4) Emphasize and strengthen students' research-based learning and self-learning ability to improve students' ability to solve complex engineering technology problems. So as to train the graduate students obtaining the reasonable structure of knowledge, good professional quality, superb design level, strong comprehensive ability. To make students with solid mathematical science and engineering science, and also have strong liberal arts knowledge and cross multidisciplinary engineering consciousness, engineering design ideas and methods, project organization and leadership ability. 
(5) Diversified evaluation methods systems' innovation and perfection. Carry out diversified assessment, through the written test, practice, live reply, book reports, practice summation and design work, changing evaluation methods of the past single way of the written examination and standard answer, so we can assess students' knowledge application ability and it is conducive to creativity thinking.

(6) Set up talents evaluation system of schools, enterprise units and teaching departments all participating in. This could make professional personnel training mode get recognition of students themselves, parents and society, can obtain employers and social's recognition, and achieve remarkable results in self-evaluation, teacher evaluation and social evaluation and other comprehensive evaluation aspects.

\section{The revision design of training mode, training plan and training scheme}

According to large scale training before implement, later conduct the excellence engineers training new model of wide caliber professional education for students' academic disciplines learning laying the solid foundation and broadening the professional orientation. Initially scheduled for the "1+3" mode, 1 years of general education, 3 years of professional education. during schooling ensure enough business practice and learning in addition to earning the basic theory knowledge and professional knowledge, depend on the various professional quality, teachers, school resources, enterprise conditions and other factors such as university-enterprise cooperation to design and implement. During the training program, basic courses, professional courses, core curriculum redetermine in accordance with the excellent engineer training requirements, fully embody the important role of comprehensive engineering practice of the engineering education concept, school curriculum, teachers, companies and social environment. Professional construction priorities reflect the core knowledge system and cross each other of the professional direction, as well as the machinery industry mainstream technology and the latest development.

\section{Training base construction and the school-enterprise cooperation mechanism}

(1) In the excellence engineers education base construction, fully play the role of school provincial experimental teaching demonstration center talents training base, through the engineering practice conditions continuously improving and the expanding of engineering training connotation, gradually establish a phased, multi-levels, modular, comprehensive, open engineering training mode, complete the conversion from the traditional way to comprehensive engineering training and make engineering training and practice throughout the whole teaching process. Promote and develop industry-university cooperative education model, co-construct and share personnel training practice base with the local well-known enterprises and other qualified enterprises. Encourage and guide students actively participating in all levels of science and technology competitions, technological innovation and training, entrepreneurship training programs and other activities, and train students' comprehensive ability and innovative spirit.

(2) About the graduation practice, ensure the implementation of time allocation, project practice and other aspects, and improve the effect. Reform the off-campus internship and the graduation design battle plan, completely enhance graduates' innovation ability and comprehensive quality by encouraging students to participate into enterprise practice, teachers' scientific research projects, the science and technology competitions. According to the track inspection of students' training quality, information feedback and performance evaluation results, provide the deepening teaching reform and improve the quality of teaching.

(3) Hiring practices experienced experts to comprehensively participate in the education guidance and teaching reform work, establish the professional industry-academic cooperation committee. Implement the school-enterprise strategic alliance, through joint related enterprises, gradually establish a stable industry-university training base, graduate employment entrepreneurial base, and 
promote the establishment of the excellence engineers training program, the industry-academia cooperation system, the co-operative education policy and other systems.

(4) The establishment of enterprise and school joint training scheme. Students accept the enterprise staff management model, participate in or refer to enterprise product development and project implementation, which specifically focuses on defining graduation design practice needs to achieve the goal and master the skills.

\section{The team construction of excellence program}

(1) Teacher teams' engineering practice consciousness and ability is the most important guarantee of excellence program implementation quality. Stable part-time staff is one of the effective measures to implement excellence program. According to the professional characteristic and the need establishing the corresponding position, hiring practice experienced senior technical talents and experts to teach or part-time.

(2) Formulate policies, implement a planned way under teachers' enterprise system, sign the agreement of university-enterprise joint training teaching practical skills, select a group of young teachers using the holiday to enterprises to carry out field work, arrange the backbone of middle-aged and young teachers to teach while working and to carry out the practice training. To solve the contradiction of teachers with high theoretical level but insufficient practical ability.

\section{The Implementation effect of excellence program}

Following the Long-term Education Reform and Development Plan (2010-2020) and the school Twelfth Five-Year development plan, persist in maintaining the training talents quality as the core, and achieved good results. Training program revision focuses on reflecting the excellence engineers' standards of the ministry of education, and builds a diversified, multi-targets talents training model. Fluid Mechanics and Fundamentals of Interchangeability and Measurement Technology are selected as provincial quality courses, form a mechanical and electrical undergraduate teaching reform experimental class, implement the tutorial system, teaching reform results are remarkable. Automation and machinery manufacturing professional obtains one of the first experimental majors of the ministry of education-autodesk company specializing in the comprehensive reform project. Three engineering practice education centers are selected as the first batch projects of national construction; mechanical engineering practice education center obtains the provincial school-enterprise cooperation and practice education base. The teacher's teaching ability development center successfully declared the applied teachers' teaching ability development center in Anhui province. Every year to support and reward the college students' science innovation and academic competitions fund amounted to more than 2000 thousand Yuan, participating students were up to million people, obtained more than 180 items honor in provincial and national competitions of 2012, including a gold medal of challenge cup.

\section{Summary}

Implementing excellence engineers training plan is a systematic project, reform affects the situation as a whole. We not only learn from other domestic colleges and academic practice experience, but also should according to the basic requirements of applied undergraduate excellence engineers training plan, combining with the own conditions of Anhui University of Science \& Technology, running environment and the characteristics of mechanical engineering, as well as the enterprise needs of current engineering machinery and other fields, develop professional cultivation scheme and standards, carry on the teaching reform, improve the university-enterprise cooperation mechanism, build a high quality faculty, establish the standards of mechanical engineering excellence engineers training program, formulate the professional training plan and the standard as well as modular treatment combining with our own school, reform all professional courses including 
the teaching contents and methods, formulate evaluation methods and incentive mechanism of our department on mechanical engineering excellence engineers training. Then explore a suitable road to develop mechanical engineering excellence engineers, and improve its training system.

\section{Acknowledgments}

This research was sponsored by Anhui Province Universities Provincial Education Research Project (Grant NO: 2015zy020), academic key teaching research project of Anhui University of Science \& Technology (Grant NO: 2015zdjy070)

\section{References}

[1]. Yan Min, He jinshe, Zhou huijuan. Thinking of Colleges and Universities Excellence Talents Training Program [J]. Journal of Zhengzhou Institute of Aeronautics Industry Management. Vol. 22 (2012) No. 06, p. 114-119.

[2]. Li Zhangjun. Innovative Technology Talents: the Priority of Talents Squad Construction [N]. People's Daily, 2010-06-18(8).

[3]. Gao Lin. Introduction to Applied Undergraduate Education [M]. Beijing: Science Press, 2007. p. 121-126.

[4]. Zhang Daliang. Implement the Education Development Programs, Accelerate the Reform and Development of Higher Engineering Education [J]. Beijing, China Higher Education Research. Vol. 30 (2011) No. 01, p. 16-19.

[5]. Lin Jian. Professional Training Scheme of Excellence Engineers Education Training Program [J]. Education Research of Tsinghua University. Vol. 25 (2011) No. 02, p. 47-55.

[6]. Han Jianhai, Zhou Zhili, Du Hui. Highlight Industry Background and Characteristics, Construct Talent Training New Mode of Excellence Program [J]. Henan Education (Higher Education). Vol. 31 (2013) No. 02, p. 7-8.

[7]. Zhang Sherong, Cui Wei. The Exploration of Graduation Design Reform Facing to Enterprise Demands [J]. Experimental Technology and Management. Vol. 28 (2011) No. 07, p. 14-17.

[8]. Liu Yuanlin, Zhang Zengfeng, Li hongtao. Mechanical "3 + 1" Talent Nurturing Mode Reform Based on Excellence Program [J]. The Education of Heilongjiang. Vol. 28 (2013) No. 01, p. 41-42. 